\title{
The Relationship Between Body Mass Index and Lower Urinary Tract Symptoms in Men
}

\author{
Ali Aslan ${ }^{1}$, Abdullah Çırakoğlu ${ }^{2}$, Yeliz Kaşko Arıc1 ${ }^{3}$ \\ ${ }^{1}$ Ordu University, Faculty of Medicine, Department of Physiology, Ordu, Turkey \\ ${ }^{2}$ Ordu University, Faculty of Medicine, Department of Urology, Ordu, Turkey \\ ${ }^{3}$ Ordu University, Faculty of Medicine, Department of Biostatistics and Medical Informatics, Ordu, Turkey \\ Received: 12 July 2019, Accepted: 10 August 2019, Published online: 28 August 2019 \\ (C) Ordu University Institute of Health Sciences, Turkey, 2019
}

\begin{abstract}
Objective: The studies evaluating, association between obesity and lower urinary tract symptoms (LUTS) are limited. Our study's objective was to determine the correlation between obesity and LUTS in men.

Methods: Information of 639 patients who were aged between 37 and 92, had not been treated for BPH before, had moderate or severe LUTS, had International Prostate Symptom Score (IPSS) $\geq 8$ and had prostate-specific antigen (PSA) value less than $4 \mathrm{ng} / \mathrm{ml}$ was evaluated retrospectively. Measured Body Mass Index (BMI) was classified in accordance with World Health Organization (WHO).

Results: A statistically significant difference was present between BMI groups with respect to post-void residual urine volume (PVR) ( $\mathrm{p}=0.017)$. PVR level of the obesity group's PVR level was found to be significantly lower when compared to the normal group $(\mathrm{p}<0.05)$. In patients with diabetes mellitus (DM), only PVR parameter among LUTS was found to differ significantly from BMI groups $(\mathrm{p}=0.037)$. In patients with DM, the mean of PVR of obese patients was detected to be significantly lower when compared to the mean of normal patients $(\mathrm{p}<0.05)$. In patients with cardiovascular disease $(\mathrm{CD})$, only Qmax and Qave parameters were found to differ significantly from BMI groups. $(p=0.001$ and $p<0.001$, respectively). In patients with $\mathrm{CD}$, the mean $\mathrm{Qmax}$ of obese patients was significantly higher than the average of normal-weight patients $(\mathrm{p}<0.05)$.

Conclusion: Although there is no association between obesity and LUTS except PVR, we think that the risk of obesity associated with DM and CD would significantly increase the risk of LUTS.
\end{abstract}

Key words: Lower urinary tract symptoms, Body mass index, Obesity, Urology

Suggested Citation: Aslan A, Cirakoglu A, Kasko Arici Y. The Relationship Between Body Mass Index and Lower Urinary Tract Symptoms in Men. Middle Black Sea Journal of Health Science, 2019; 5(2):138144

\section{Address for correspondence /reprints:}

Ali Aslan

Telephone number: +90 (452) 2265200

E-mail: draslan@yahoo.com

DOI: $10.19127 / \mathrm{mbsjohs.591267}$

\section{Introduction}

LUTS are one of the most important health problems frequently seen in adult men and affecting quality of life negatively. It is known that older men are suffering from at least one of LUTS. The level of discomfort may vary from "too mild to negligible" to "severe discomfort". The change and development of information about LUTS over time has led to some problems in the definition and terminology of LUTS, and a number of studies were published by Standardization Subcommittee of "International Continence Association (ICS)" to eliminate the terminology problems.

"According to ICS 2002 standardization report", LUTS classification is as follows (Abrams 
et al., 2002);

I. Symptoms of filling phase (urinary incontinence, nocturia, increase in the frequency of daytime urination, urinary compression)

II. Symptoms of voiding phase (terminal drip, delayed urine initiation, forked-scattered urine flow, discontinuous urine flow, poor urine flow, forced urine discharge)

III. Post-voiding symptoms (post-void drip, feeling of incomplete urinary excretion).

The prevalence of these symptoms detected in both males and females has been reported to be approximately $19.2 \%$ of males and $13.7 \%$ of females, although it has changed from country to country in the population screenings (Abrams et al., 2002). However, the high prevalence of disease and drug use accompanied by aging contributes to the increase in the prevalence of LUTS during the old age (Takeda et al., 2003).

Obesity has been defined as "excessive or abnormal increase of body fat content to disrupt health" by WHO. Obesity is a condition which the body fat ratio is $25 \%$ for men and $35 \%$ for women (Yuksel, 2016). The study of "Turkey Obesity Profile" performed on 13878 individuals over the age of 20 in 6 provinces (Gaziantep, Konya, Denizli, Kastamonu, Kirklareli and Istanbul) by Turkish

Association for the Study of Obesity (TASO) between 2000-2005 years. It was found that $30.9 \%$ of the individuals had BMI $>25 \mathrm{~kg} / \mathrm{m}^{2}$. Obesity causes damage to the urethral mucosa, decrease in the amount of collagen and loss of urethra elasticity. However, obesity is an important predisposing factor for urinary incontinence and increases the severity of the condition. Chronic strains caused by pelvic muscles and nerves affected by excessive weight trigger stress, stretching and weakening. Body mass index showed significantly higher values in stress urinary incontinence (Bilge and Beji, 2016).

Obesity and LUTS are frequent in elder men and might significantly influence their quality of life. In the cohort studies, it was reported that there was a positive association between LUTS and anthropometric obesity measurements (Giovannucci et al., 1994; Gann et al., 1995). In addition, Hammarsten et al. suggested in a clinicalbased study that an expanded prostate may be the consequence of prostate development, impaired insulin management and other sides of the metabolic syndrome according to the results of 158 patients more frequently identified in men with constituents of a metabolic syndrome like hypertension needing therapy, insulin-dependent diabetes mellitus (IDDM), low HDL-cholesterol levels, obesity and high fasting insulin levels (Hammarsten et al., 1998).

There are limited number of studies investigating the association between obesityassociated diseases and LUTS in the literature. Moreover, the number of studies emphasizing which LUTS are affected is much less. It is observed in the literature that there are different results between obesity and accompanying diseases, and LUTS development. The aim of our study is to determine the association between obesity and LUTS in men.

\section{Methods}

This study was a cross-sectional study conducted from January 2015 to June 2018. Data of 639 patients who admitted to Urology Clinic of Medical Faculty Hospital in Ordu University, were aged between 37 and 92, had not been treated for BPH before, had moderate or severe LUTS, had IPSS $\geq 8$ and had PSA value less than $4 \mathrm{ng} / \mathrm{ml}$ was evaluated retrospectively. This planned research complies to the Declaration of Helsinki rules including patient's rights and ethical guidelines and were confirmed by Local Ethics Committee of Ordu University (Date: Dec 2018, Number: 2018/265).

639 male patients between the ages of 37 and 92 were evaluated. BMI, which is calculated by dividing the weight in kilograms by the square of the height in meter, is classified according to WHO: underweight $(<18.5 \mathrm{~kg} / \mathrm{m} 2)$, normal weight (18.5-24.9 kg/m2), overweight (25 to $29.9 \mathrm{~kg} / \mathrm{m} 2$ ) and obese $(>30 \mathrm{~kg} / \mathrm{m} 2)$, however there wasn't any underweight patient in this study.

The patients in the study were split into two groups as with or without hypertension (HT), diabetes mellitus (DM), cardiovascular disease (CD) and drug use (DU). Ages, IPSS values, prostate volumes, urinary flow rates (Qmax, Qaverage), PVR and PSA data of patients in each group were evaluated.

In patients with $\mathrm{HT}, \mathrm{DM}, \mathrm{CD}$ and positive DU, LUTS variables were examined in terms of BMI groups.

\section{Statistical Analysis}

For the continuous variables, KolmogorovSmirnov test for normal distribution control of the data and Levene test for the homogeneity of the group variances were performed. Independent samples t-test was utilized to compare two groups. One-way ANOVA and following Tukey post-hoc 
test were used to compare the averages of more than two independent groups. Pearson correlation coefficients were calculated to evaluate the relationships among the continuous variables. Pearson's chi-square test $\left(\chi^{2}\right)$ was used to determine the relationship between the categorical variables. The statistical significance level was accepted as $5 \%$ for calculations and interpretations. All data analyses were conducted using the SPSS (Demo version 25.0, IBM Corp., Armonk, NY, USA) statistical software.

\section{Results}

According to one-way ANOVA, no statistically significant difference was observed between BMI groups with respect to the mean age $(p=0.091)$. When the prevalences were evaluated, the prevalence of normal weight, overweight and obese groups were $19.4 \%(\mathrm{n}=124), 49.5 \%(\mathrm{n}=$ $316)$ and $31.1 \%(n=199)$, respectively (Table 1$)$.

Table 1. Comparison of the prevalences and ages of the patients among BMI groups

\begin{tabular}{lcccc} 
& $\mathrm{n}(\%)$ & Mean \pm SD & Min.-Max. & $\mathrm{p}$ \\
\cline { 2 - 5 } Normal weight & $124(19.4)$ & $63.00 \pm 10.64$ & $44.0-92.0$ & \\
Overweight & $316(49.5)$ & $62.00 \pm 9.21$ & $39.0-85.0$ & $0.091^{\mathrm{NS}}$ \\
Obese & $199(31.1)$ & $61.00 \pm 9.12$ & $37.0-84.0$ & \\
Total & $639(100.0)$ & $62.00 \pm 9.52$ & $37.0-92.0$ & \\
\hline
\end{tabular}

NS; $>0.05$

One-way ANOVA test was performed to detect statistically significant difference among BMI subgroups in terms of LUTS. No statistically significant difference was detected among BMI groups for all variables, except PVR ( $>>0.05)$. A statistically significant difference was observed among BMI groups with respect to PVR $(\mathrm{p}=0.017)$. According to Tukey test, no significant difference was found between the normal group and overweight group ( $p>0.05)$; however, PVR level of the obesity group was detected to be significantly lower than normal group $(\mathrm{p}<0.05)$ (Table 2).

IPSS was divided into mild (0-7), moderate (8$19)$ and severe (20-35) symptoms. Chi-square test was performed to analyze the frequency distribution of IPSS groups in BMI groups. It was observed that the frequency distribution of IPSS groups did not change in terms of BMI groups $(\mathrm{p}=0.730)$ (Table 3).

Table 2. Descriptive statistics and comparison results for LUTS among BMI groups

\begin{tabular}{|c|c|c|c|c|}
\hline & $\begin{array}{l}\text { Normal weight } \\
\qquad(n=124)\end{array}$ & $\begin{array}{l}\text { Overweight } \\
\quad(n=316)\end{array}$ & $\begin{array}{l}\text { Obese } \\
(n=199)\end{array}$ & $\mathrm{p}$ \\
\hline & Mean \pm SD & Mean \pm SD & Mean \pm SD & \\
\hline IPSS-obstructive total & $6.28 \pm 5.94$ & $5.63 \pm 4.84$ & $5.44 \pm 4.96$ & $0.333^{\mathrm{NS}}$ \\
\hline IPSS-irritative total & $6.09 \pm 3.16$ & $6.27 \pm 3.64$ & $6.26 \pm 3.31$ & $0.879^{\mathrm{NS}}$ \\
\hline IPSS total & $11.94 \pm 6.74$ & $11.74 \pm 6.85$ & $11.60 \pm 7.18$ & $0.913^{\mathrm{NS}}$ \\
\hline Prostate volume & $34.09 \pm 16.15$ & $37.02 \pm 18.73$ & $38.10 \pm 25.57$ & $0.822^{\mathrm{NS}}$ \\
\hline Qmax & $14.38 \pm 6.54$ & $15.88 \pm 7.53$ & $16.66 \pm 9.89$ & $0.229^{\mathrm{NS}}$ \\
\hline Qave & $6.27 \pm 3.68$ & $7.09 \pm 4.39$ & $6.87 \pm 3.07$ & $0.051^{\mathrm{NS}}$ \\
\hline PVR & $43.47^{ \pm} 97.55^{\mathrm{a}}$ & $33.94 \pm 51.41^{\text {ab }}$ & $23.54 \pm 38.95^{\mathbf{b}}$ & 0.017* \\
\hline PSA & $2.01 \pm 2.05$ & $2.29 \pm 4.23$ & $2.37 \pm 4.37$ & $0.333^{\mathrm{NS}}$ \\
\hline
\end{tabular}

NS; $>0.05, * ; p<0.05$, According to Tukey test, means that do not share a common letter are significantly different $(\mathrm{p}<0.05)$

Table 3. Frequency distribution of IPSS total score for the patients in BMI groups

\begin{tabular}{lcccc} 
& Normal weight & Overweight & Obese & $\mathrm{p}$ \\
\cline { 2 - 5 } Mild & $36(5.6 \%)$ & $108(16.9 \%)$ & $69(10.8 \%)$ & \\
Normal & $70(11.0 \%)$ & $160(25.0 \%)$ & $97(15.2 \%)$ & $0.730^{\mathrm{NS}}$ \\
Severe & $18(2.8 \%)$ & $48(7.5 \%)$ & $33(5.2 \%)$ & \\
\hline \multicolumn{1}{c}{ NS; $\mathrm{p}>0.05$} & & & &
\end{tabular}


According to One-way ANOVA results, there was no statistically significant difference among BMI groups in terms of LUTS parameters in HT and DU positive patients ( $p>0.05)$. In patients with positive DM, only PVR parameter showed a significant change among BMI groups $(p=0.037)$, yet there was no significant difference in the remaining parameters $(p>0.05)$. In patients with $\mathrm{DM}$, the mean PVR of obese patients was significantly decreased when compared to the average of normal patients $(\mathrm{p}<0.05)$. In the patients with positive $\mathrm{CD}$, only Qmax and Qave parameters showed a significant change among BMI groups $(\mathrm{p}=0.001$ and $\mathrm{p}<0.001$, respectively). In patients having $\mathrm{CD}$, the mean Qmax of obese patients was significantly increased when compared to that of normal-weight patients $(\mathrm{p}<0.05)$. The mean $\mathrm{Qmax}$ of overweight patients was not significantly different from normal and obese patients ( $p>0.05)$. In patients with $\mathrm{CD}$, there was no significant difference between overweight and obese patients ( $>0.05)$ while they had significantly higher Qave average than normal weight patients $(\mathrm{p}<0.05)$ (Table 4).

Table 4. Descriptive statistics and comparison results of the patients with HT, DM, CD and DU in BMI groups

\begin{tabular}{|c|c|c|c|c|c|c|c|c|c|c|c|c|}
\hline \multirow{4}{*}{$\begin{array}{l}\dot{n} \\
\dot{\tilde{n}} \\
\hat{\theta}\end{array}$} & \multicolumn{3}{|c|}{$\mathrm{HT}+$} & \multicolumn{3}{|c|}{$\mathrm{DM}+$} & \multicolumn{3}{|c|}{$\mathrm{CD}+$} & \multicolumn{3}{|c|}{$\mathrm{DU}+$} \\
\hline & $\mathrm{n}$ & Mean \pm SD & $\mathrm{p}$ & $\mathrm{n}$ & Mean \pm SD & $\mathrm{p}$ & $\mathrm{n}$ & Mean \pm SD & $\mathrm{p}$ & $\mathrm{n}$ & Mean \pm SD & $\mathrm{p}$ \\
\hline & 33 & $6.73 \pm 5.87$ & & 18 & $5.72 \pm 4.20$ & & 15 & $11.27 \pm 11.16^{\mathrm{A}}$ & & 48 & $7.29 \pm 7.38$ & \\
\hline & 113 & $5.48 \pm 4.71$ & $0.406^{\mathrm{NS}}$ & 62 & $5.10 \pm 4.14$ & $0.768^{\mathrm{NS}}$ & 60 & $5.43 \pm 4.61^{\mathrm{B}}$ & $0.004^{* *}$ & 115 & $6.87 \pm 4.78$ & $0.771^{\mathrm{NS}}$ \\
\hline$=\mathrm{O}$ & 92 & $6.11 \pm 5.22$ & & 63 & $5.67 \pm 5.42$ & & 34 & $5.35 \pm 5.75^{\mathrm{B}}$ & & 75 & $6.28 \pm 4.60$ & \\
\hline \multirow{3}{*}{$\begin{array}{c}\tilde{n}_{\hat{n}} \cdot \dot{\mathrm{N}} \\
\mathrm{O} \\
\mathrm{OW} \\
\mathrm{O}\end{array}$} & 33 & $6.18 \pm 3.14$ & & 18 & $6.83 \pm 3.30$ & & 15 & $6.47 \pm 4.02$ & & 238 & $6.77 \pm 5.34$ & \\
\hline & 113 & $6.51 \pm 3.31$ & $0.873^{\mathrm{NS}}$ & 62 & $6.84 \pm 3.35$ & $0.981^{\mathrm{NS}}$ & 60 & $6.80 \pm 3.31$ & $0.867^{\mathrm{NS}}$ & 48 & $6.23 \pm 3.23$ & $0.909^{\mathrm{NS}}$ \\
\hline & 92 & $6.48 \pm 3.26$ & & 63 & $6.73 \pm 3.13$ & & 34 & $7.03 \pm 3.40$ & & 115 & $6.46 \pm 3.32$ & \\
\hline \multirow{3}{*}{ 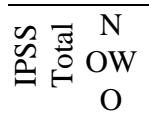 } & 33 & $12.85 \pm 7.83$ & & 18 & $12.44 \pm 6.16$ & & 15 & $15.27 \pm 9.45$ & & 75 & $6.32 \pm 3.35$ & \\
\hline & 113 & $11.97 \pm 6.66$ & $0.751^{\mathrm{NS}}$ & 62 & $11.94 \pm 6.34$ & $0.921^{\mathrm{NS}}$ & 60 & $12.25 \pm 6.61$ & $0.337^{\mathrm{NS}}$ & 48 & $12.75 \pm 7.05$ & $0.732^{\mathrm{NS}}$ \\
\hline & 92 & $12.59 \pm 7.47$ & & 63 & $12.40 \pm 7.57$ & & 34 & $12.18 \pm 7.71$ & & 115 & $13.33 \pm 6.71$ & \\
\hline \multirow{3}{*}{ 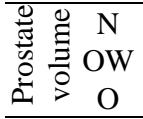 } & 33 & $35.76 \pm 15.72$ & & 18 & $38.78 \pm 17.64$ & & 15 & $34.27 \pm 14.86$ & & 75 & $12.57 \pm 6.85$ & \\
\hline & 113 & $35.24 \pm 17.10$ & $0.211^{\mathrm{NS}}$ & 62 & $32.24 \pm 13.23$ & $0.164^{\mathrm{NS}}$ & 60 & $35.85 \pm 15.33$ & $0.758^{\mathrm{NS}}$ & 48 & $37.77 \pm 17.90$ & $0.684^{1}$ \\
\hline & 92 & $40.85 \pm 31.04$ & & 63 & $39.06 \pm 27.08$ & & 34 & $38.62 \pm 30.76$ & & 115 & $41.10 \pm 21.28$ & \\
\hline \multirow{3}{*}{$\stackrel{\mathscr{g}}{\sigma}$} & 33 & $14.01 \pm 4.58$ & & 18 & $14.53 \pm 5.97$ & & 15 & $9.93 \pm 4.78^{\mathrm{B}}$ & & 75 & $40.52 \pm 26.42$ & \\
\hline & 113 & $15.18 \pm 6.62$ & $0.301^{\mathrm{NS}}$ & 62 & $16.00 \pm 7.08$ & $0.439^{\mathrm{NS}}$ & 60 & $14.03 \pm 6.17^{\mathrm{AB}}$ & $0.001^{* *}$ & 48 & $13.59 \pm 5.17$ & $0.687^{\mathrm{NS}}$ \\
\hline & 92 & $16.09 \pm 7.64$ & & 63 & $14.58 \pm 6.22$ & & 34 & $17.12 \pm 7.06^{\mathrm{A}}$ & & 115 & $13.61 \pm 6.77$ & \\
\hline \multirow{3}{*}{$\stackrel{\circ}{\tilde{E}}$} & 33 & $5.95 \pm 2.42$ & & 18 & $5.88 \pm 2.89$ & & 15 & $3.87 \pm 2.03^{\mathrm{B}}$ & & 75 & $14.70 \pm 12.15$ & \\
\hline & 113 & $6.57 \pm 2.97$ & $0.535^{\mathrm{NS}}$ & 62 & $7.98 \pm 7.05$ & $0.093^{\mathrm{NS}}$ & 60 & $6.12 \pm 2.30^{\mathrm{A}}$ & $\mathrm{p}<0.001^{* * * *}$ & 48 & $5.41 \pm 2.55$ & $0.477^{\mathrm{NS}}$ \\
\hline & 92 & $6.56 \pm 2.96$ & & 63 & $6.16 \pm 2.79$ & & 34 & $7.28 \pm 2.97^{\mathrm{A}}$ & & 115 & $6.16 \pm 5.51$ & \\
\hline \multirow{3}{*}{$\sum_{2}^{a}$} & 33 & $26.67 \pm 33.43$ & & 18 & $44.17 \pm 41.92^{\mathrm{A}}$ & & 15 & $38.47 \pm 26.82$ & & 75 & $5.57 \pm 2.30$ & \\
\hline & 113 & $30.24 \pm 43.06$ & $0.170^{\mathrm{NS}}$ & 62 & $31.85 \pm 41.25 \mathrm{AB}$ & $0.037^{*}$ & 60 & $29.38 \pm 43.44$ & $0.081^{\mathrm{NS}}$ & 47 & $38.28 \pm 53.86$ & $0.271^{\mathrm{NS}}$ \\
\hline & 92 & $20.26 \pm 31.55$ & & 63 & $20.24 \pm 31.55^{\text {В }}$ & & 34 & $15.79 \pm 20.12$ & & 115 & $42.44 \pm 54.32$ & \\
\hline \multirow{3}{*}{$\underset{\mathscr{\Omega}}{\mathbb{2}}$} & 33 & $1.99 \pm 1.80$ & & 18 & $2.41 \pm 2.49$ & & 15 & $1.76 \pm 1.32$ & & 75 & $29.87 \pm 48.18$ & \\
\hline & 111 & $1.88 \pm 2.28$ & $0.136^{\mathrm{NS}}$ & 61 & $1.51 \pm 1.22$ & $0.177^{\mathrm{NS}}$ & 60 & $1.92 \pm 1.66$ & $0.383^{\mathrm{NS}}$ & 48 & $2.37 \pm 2.27$ & $0.917^{\mathrm{NS}}$ \\
\hline & 90 & $3.02 \pm 6.07$ & & 63 & $1.75 \pm 2.00$ & & 32 & $2.70 \pm 4.49$ & & 114 & $2.57 \pm 2.86$ & \\
\hline
\end{tabular}

N; Normal weight, OW; Overweight; O; Obese, Hypertension; HT, DM; Diabetes mellitus, CD; Cardiovascular disease, DU; Drug use (Prostate), NS; $>>0 ; 05,{ }^{*} ; \mathrm{p}<0.05$, **; $\mathrm{p}<0.01$, ***; $<<0.001$, According to Tukey test, means that do not share a common letter are significantly different $(\mathrm{p}<0.05)$

Pearson correlation coefficients were calculated to investigate the correlations between LUTS and BMI. The correlation coefficients given in Table 5 represent that LUTS variables are very weakly correlated with BMI and most of them have no statistically significant association $(p>0.05)$. The correlation coefficients of some variables that are statistically significantly correlated with BMI are quite small (PVR, $\mathrm{r}=-0.105 ; \mathrm{p}=0.008)$. These associations have emerged from the high sample size and are too weak to be considered in practice (Table 5).
Table 5. Correlation coefficients between BMI and LUTS ( $\mathrm{n}=639$ )

\begin{tabular}{lcc}
\hline & $\mathrm{r}$ & $\mathrm{p}$ \\
\hline Age & -0.086 & $\mathbf{0 . 0 3 0} *$ \\
IPSS-obstructive total & -0.075 & 0.058 \\
IPSS-irritative total & 0.075 & 0.058 \\
IPSS total & 0.002 & 0.956 \\
Prostate volume & 0.057 & 0.149 \\
Qmax & 0.093 & $\mathbf{0 . 0 1 9} *$ \\
Qave & 0.036 & 0.358 \\
PVR & -0.105 & $\mathbf{0 . 0 0 8} *$ \\
PSA & -0.100 & $\mathbf{0 . 0 1 2} *$ \\
\hline
\end{tabular}

r; Pearson correlation coefficient, ${ }^{*} ; \mathrm{p}<0.05, * * ; \mathrm{p}<0.01$ 


\section{Discussion}

Our study was realized to determine the association between BMI and LUTS in men. According to the results of our study, there was a statistically significant difference among BMI groups in terms of PVR ( $\mathrm{p}=0.017)$. PVR level of the obesity group was found to be significantly decreased when compared to the normal group $(p<0.05)$. Although many factors have been charged until now, the real causes of LUTS are not known precisely and LUTS is considered as a multifactorial event. The two risk factors taking role in the etiology of BPH are aging and the presence of functional testes (androgens). In recent years, the importance of metabolic syndrome, DM, obesity, smoking and lifestyle, heredity and genetic factors are stated as other etiological factors (Konwar et al., 2008; Parsons, 2010; Cetinkaya and Oztekin, 2011).

In many studies, a significant relationship was detected between obesity and LUTS (Altunkaynak and Ozbek, 2006). In a study conducted by Bart et al. in France, the prevalence of LUTS was found to be $44 \%$ (Bart et al., 2008). In addition, severe weight loss in morbidly obese patients with LUTS significantly was observed to reduce intravesical pressure. This is a step that emphasizes the importance of obesity-induced intra-abdominal pressure in the development of stress LUTS (Yalcin, 2009). In a case-control study performed on African-American men, Sarma et al. expressed that BMI was directly related to prostate volume (Sarma et al., 2002). No relation was found between BMI and LUTS in the studies realized in China and Greece (Signorello et al., 1999; Dahle et al., 2002). While obesity reduces free and total testosterone and serum globulin binding protein levels, it increases estrogen levels as well as free and total estradiol concentrations (Pasquali et al., 1991). Higher estrogen levels can affect prostate cell growth in the environment of low testosterone levels due to age-related and obesity. In particular, it increases the rate of estrogen/androgen in abdominal obesity and may increase the sympathetic nerve activity, which is known to affect both the development of BPH and the severity of LUTS (Giovannucci et al., 1994; Barqawi et al., 2005). In our study, no significant relationship was observed between prostate volume and obesity. However, a statistically significant difference was detected between obesity and PVR, which is one of LUTS $(\mathrm{p}=0.017)$.

Serum PSA levels can be affected by many factors such as age, prostate volume, and obesity. Nowadays, it has been reported in many studies that there has been a negative correlation between PSA levels and BMI (Barqawi et al., 2005; Kristal et al., 2006). However, Ochiai et al. expressed that anthropometric parameters were not directly correlated with PSA levels and BMI (Ochiai et al., 2005). Although obesity is an important anthropometric factor in the metabolic syndrome, there are complex associations among individual anthropometric parameters, partly due to their association with obesity. Crystal et al. declared that PSA levels were $0.2-0.4 \mathrm{ng} / \mathrm{ml}$ lower in obese patients compared to normal weight (Kristal et al., 2006). However, they informed that the magnitude of the association between serum PSA levels and the presence of each metabolic component could not be precisely determined. In our study, no significant relationship was detected between serum PSA level and BMI.

Obesity, which is a crucial risk factor of metabolic syndrome, causes hypertension, insulin resistance, hypertriglyceridemia and low HDL cholesterol. Metabolic syndrome of which prevalence has increased progressively in the world is seen in $28 \%$ of men over the age of 30 in Turkey (Onat et al., 2002). While LUTS in elderly men have made think direct benign prostate hyperplasia in previous years, later studies have proved that chronic illnesses such as diabetes, heart disease, and metabolic syndrome components, lifestyle factors such as alcohol, smoking and physical activity are effective in the development of LUTS (Chapple and Roehrborn, 2006; Fitzgerald et al., 2007).

In our study, it was found that only PVR parameter in LUTS was significantly different among BMI groups in patients with DM ( $\mathrm{p}=0.037)$, however there was no significant difference in the remaining parameters $(p>0.05)$. In patients with DM, the mean PVR of obese patients was significantly lower than the average of normal patients $(\mathrm{p}<0.05)$. In patients with $C D$, only Qmax and Qave parameters showed a significant difference among BMI groups $(\mathrm{p}=0.001$ and $\mathrm{p}<0.001$, respectively). In patients with $\mathrm{CD}$, the mean Qmax of obese patients was significantly increased when compared to that of normal-weight patients $(\mathrm{p}<0.05)$.

\section{Conclusion}

All in all, although there is no relationship between obesity and LUTS except PVR, we believe that obesity associated diabetes mellitus 
and cardiovascular diseases will increase the risk of LUTS development significantly. We think that our study will provide a significant contribution to the literature in terms of the high number of patients, the high number of parameters evaluated and the different results. In the future, more studies are needed to determine the etiology of LUTS development and contribute to the prevention of LUTS development.

Ethics Committee Approval: Ethics committee approval was received for this study from Ordu Clinical Research Ethics Committee of ORDU University. Ethics no: 2018/265

Peer-review: Externally peer-reviewed.

Author Contributions: Externally peer-reviewed. Author Contributions: Concept- Y.K.A., A.A., A.Ç, Design- A.Ç., Y.K.A Supervision-Y.K.A., A.A., A.Ç, Literature Review- A.A., A.Ç, WritingA.A., Y.K.A, Critical Review- A.Ç.

Conflict of Interest: No conflict of interest was declared by the author.

Financial Disclosure: The authors declared that this study hasn't received no financial support.

\section{References}

Abrams P, Cardozo L, Fall M, Griffiths D, Rosier $\mathrm{P}$, Ulmsten $\mathrm{U}$, et al. The standardisation of terminology of lower urinary tract function: report from the Standardisation Sub-committee of the International Continence Society. Neurourol Urodynam. 2002;21(2):167-78.

Altunkaynak BZ, Ozbek E. Obesity: Causes and Treatment Alternatives. Van Med J. 2006;13(4):138-42.

Barqawi AB, Golden BK, O'Donnell C, Brawer MK, Crawford ED. Observed effect of age and body mass index on total and complexed PSA: analysis from a national screening program. Urology. 2005;65(4):708-12.

Bart S, Ciangura C, Thibault F, Cardot V, Richard F, Basdevant A, et al. Stress urinary incontinence and obesity. Prog Urol. 2008;18(8):493-8.

Bilge C, Beji NK. Obesity and Lower Urinary Tract Symptoms in Women. Florence Nightingale J Nurs. 2016;24(2):72-9.

Chapple CR, Roehrborn CG. A shifted paradigm for the further understanding, evaluation, and treatment of lower urinary tract symptoms in men: focus on the bladder. Eur Urol. 2006;49(4):651-8.
Cetinkaya M, Oztekin V. Benign prostatic hyperplasia and heredity. Bull Urooncol. 2011;4:20-2.

Dahle SE, Chokkalingam AP, Gao YT, Deng J, Stanczyk FZ, Hsing AW. Body size and serum levels of insulin and leptin in relation to the risk of benign prostatic hyperplasia. $\mathrm{J}$ Urol. 2002;168(2):599-604.

Fitzgerald MP, Link CL, Litman HJ, Travison TG, McKinlay JB. Beyond the lower urinary tract: the association of urologic and sexual symptoms with common illnesses. Eur Urol. 2007;52(2):407-15.

Gann PH, Hennekens CH, Grodstein F, Stampfer MJ, Longcope C, Verhoek-Oftedahl W. A prospective study of plasma hormone levels, nonhormonal factors, and development of benign prostatic hyperplasia. Prostate. 1995;26(1):40-9.

Giovannucci E, Rimm EB, Chute CG, Kawachi I, Colditz GA, Stampfer MJ, et al. Obesity and benign prostatic hyperplasia. Am J Epidemiol. 1994;140(11):989-1002.

Hammarsten J, Högstedt B, Holthuis N, Mellström D. Components of the metabolic syndrome risk factors for the development of benign prostatic hyperplasia. Prostate Cancer P D. 1998;1(3):157.

Konwar R, Chattopadhyay N, Bid HK. Genetic polymorphism and pathogenesis of benign prostatic hyperplasia. BJU Int. 2008;102(5):536-44.

Kristal AR, Chi C, Tangen CM, Goodman PJ, Etzioni R, Thompson IM. Associations of demographic and lifestyle characteristics with prostate-specific antigen (PSA) concentration and rate of PSA increase. Cancer. 2006;106(2):320-8.

Ochiai A, Fritsche HA, Babaian RJ. Influence of anthropometric measurements, age, and prostate volume on prostate-specific antigen levels in men with a low risk of prostate cancer. Urology. 2005;66(4):819-23.

Onat A, Ceyhan K, BaSar O, Erer B, Toprak S, Sansoy V. Metabolic syndrome: major impact on coronary risk in a population with low cholesterol levels a prospective and crosssectional evaluation. Atherosclerosis. 2002;165(2):285-92.

Parsons JK. Benign prostatic hyperplasia and male lower urinary tract symptoms: epidemiology and risk factors. Curr Blad Dysfunct Rep. 2010;5(4):212-8. 


\section{LUTS and BMI}

Pasquali R, Casimirri F, Cantobelli S, Melchionda N, Morselli Labate AM, Fabbri R, et al. Effect of obesity and body fat distribution on sex hormones and insulin in men. Metabolism. 1991;40(1):101-4.

Sarma AV, Jaffe CA, Schottenfeld D, Dunn R, Montie JE, Cooney KA, et al. Insulin-like growth factor-1, insulin-like growth factor binding protein-3, and body mass index: clinical correlates of prostate volume among Black men. Urology. 2002;59(3):362-7.

Signorello LB, Tzonou A, Lagiou P, Samoli E, Zavitsanos $\mathrm{X}$, Trichopoulos $\mathrm{D}$. The epidemiology of benign prostatic hyperplasia: a study in Greece. BJU Int. 1999;84(3):286-91.

Takeda M, Araki I, Kamiyama M, Takihana Y, Komuro M, Furuya Y. Diagnosis and treatment of voiding symptoms. Urology. 2003;62(5):119.

Yalcin O, editor. Basic Urogynecology. Istanbul: Nobel Medical Publishing; 2009.p.20-22.

Yuksel A. Nutritional Status of a Morbid Obese Patient After Three Years of Bariatric Surgery: Case Report. Izmir Katip Celebi Univ Fac Health Sci J. 2016; 1(1): 39-45. 